\title{
ANALYSING IT FUNCTIONALITY GAPS FOR MAINTENANCE MANAGEMENT
}

\author{
Kans, Mirka ${ }^{a}$ and Ingwald, Anders ${ }^{b}$ \\ ${ }^{a}$ School of Technology and Design, Växjö University, Luckligs plats 1, S-351 95 Växjö, Sweden. \\ ${ }^{b}$ School of Technology and Design, Växjö University, Luckligs plats 1, S-351 95 Växjö, Sweden.
}

\begin{abstract}
Several studies have been carried out for describing the functionality and use of computerised maintenance management systems. A major drawback of these studies is that they do not reveal the actual support for maintenance management. To describe the full situation, the gaps between required support and actual support have to be determined. The gaps are of two kinds: 1) Between the functionality included in the IT system and the functionality required, and 2) Between the functionality included in the IT system and the functionality actually used. To reach a better understanding of the utilisation of IT in maintenance management, the existence of these gaps must be further explored. In this paper, we will study the existence of functionality gaps in maintenance management IT applications using data from a web-based questionnaire survey conducted in Swedish industry. Results show that the IT systems in general provide good support for maintenance management, thus low degree of functionality gaps. However, most commonly unused function was failure cause and consequence analysis and the most commonly unused information was maintenance improvement suggestions. When comparing the results with respect to type of IT system used, some significant differences was revealed, indicating that ERPsystems and production systems do not include all required information for maintenance management. Next step will be to further study the reasons behind the differences in gaps by conducting additional interviews.
\end{abstract}

Key Words: Maintenance Management, Information Technology, Software Functionality Gap, Survey

\section{INTRODUCTION}

The importance of enterprise information technology (IT) systems has increased in order to meet the demands set by the users. It is for instance shown that investments in IT have a positive correlation to company profitability and competitiveness [1]. This is the case also for maintenance management IT (MMIT), i.e. applications used for maintenance management purposes such as computerised maintenance management systems (CMMS) and maintenance management or asset management modules in enterprise resource planning (ERP) systems. The literature reports positive correlations between high use of IT in maintenance and high maintenance performance [2-3]. Success stories of MMIT implementation are found in for instance [4-7].

An important aspect to consider for being able to take full advantage of IT is the matching of IT functionality to IT requirements. Appropriate mapping of IT requirements for achieving the business goals which are set would avoid both overfitting and under-fitting of IT resources compared to actual needs. In maintenance, several studies have been carried out for describing the use and functionality of computerised systems; see e.g. [7-10]. A major drawback of these studies is that their inability to reveal the actual support for maintenance management. To describe the full situation, the gaps between required support and actual support has to be determined.

In this paper, we will study the existence of functionality gaps in maintenance management IT. The disposition of the paper is the following: In section 2 theory concerning IT functionality gaps is presented and four research questions concerning functionality gaps are formulated. A questionnaire survey of MMIT use is presented in section 3 . This survey serves as the basis for analysing the existence of functionality gaps. Results and implications are presented in section 4. 


\section{IT FUNCTIONALITY GAPS}

A common way to describe the dependencies between an enterprise or business and their IT systems is in form of the sociotechnical system. Three subsystems comprise the socio-technical system: the human activity system (HAS), the information system (IS) and the information technology system (ITS) [11]. The HAS consists of people performing a collection of activities and is synonymous to the term business process. The IS supports the HAS with information processing, as it is a system of communication between people. Communication is enabled by technology represented as the ITS.

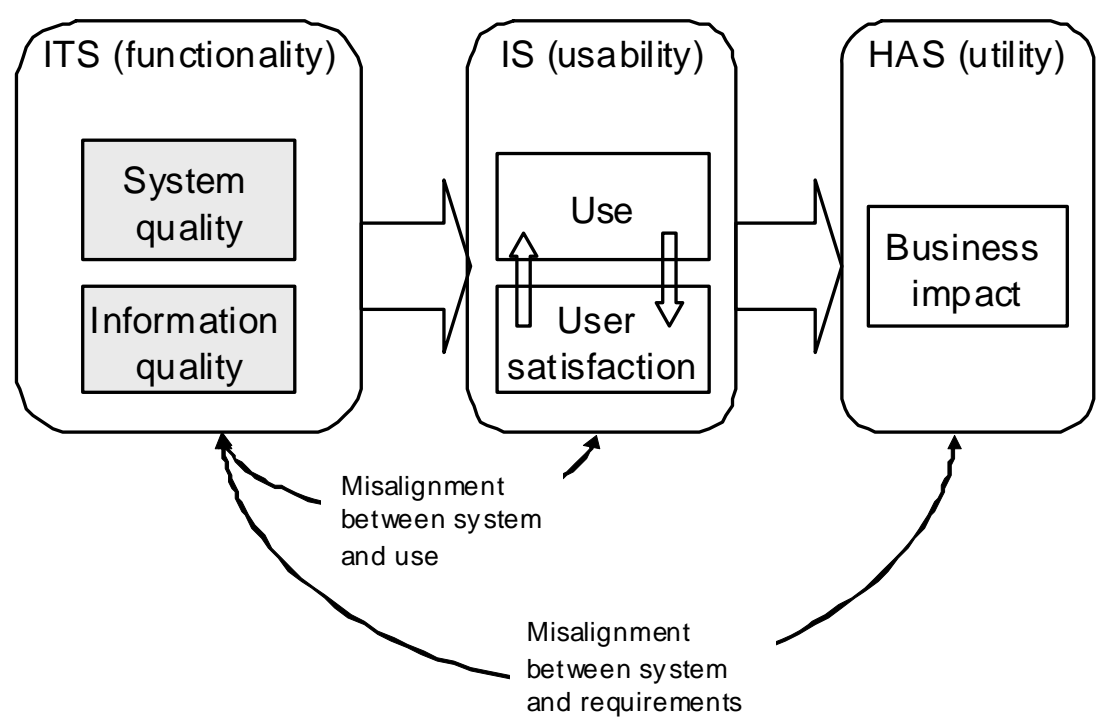

For an IS to be successful, it has to be aligned with the HAS. In this context, the properties of functionality, usability and utility could be considered. BeynonDavies connects in [11] the three properties with the socio-technical system and applies this as a framework to understand the Information Systems Success Model by DeLone and McLean [12], see Figure 1. This model comprises two issues of technical nature: the systems quality and the information quality. These will influence the use and user satisfaction with the information system, and finally impact the individual and organisation as a whole. The two latter issues are in Figure 1 collapsed into one: the business impact.

Figure 1. Misalignments recognised between different systems.

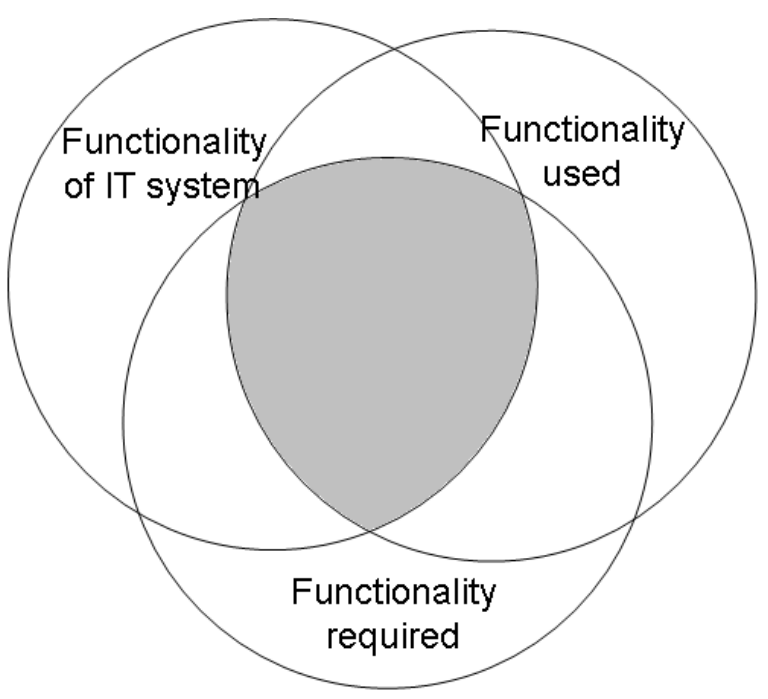

The functionality is connected to the quality of ITS and the information it handles, while usability is connected to the use and user satisfaction of the ITS. The utility describes the impact of the ITS on the HAS in form of business impact. We can recognise misalignments as gaps between the three systems. The gaps could be of two kinds: 1) Between the functionality included in the IT system and the functionality required, and 2) Between the functionality included in the IT system and the functionality actually used. How the gaps are interconnected is illustrated in Figure 2. The true utilisation of the IT system is found in the intersection of the factors to consider, in the figure marked as grey. Obviously, we strive for a situation where the three circles overlap as much as possible. Knowing the type and distance of the gap and how the gaps are varying with for instance type of application is important in order to understand the true utilisation of IT within a business. In this paper different types of maintenance management IT systems are investigated.

Figure 2. Gaps between required IT support and actual IT support

For maintenance management IT, two questions regarding the system quality are formulated:

Research question 1a: Does a gap between IT system functionality coverage and IT system functionality demands exist? (RQ1a).

Research question 1b: Does a gap between IT system functionality coverage and IT system functionality use exist? (RQ1b). 
In addition, two questions regarding the information quality are formulated:

Research question 2a: Does a gap between information coverage and information demands exist? (RQ2a).

Research question 2b: Does a gap between information coverage and information use exist? (RQ2b).

\section{DATA GATHERING AND ANALYSIS}

In this section data from a web-based questionnaire survey are presented and analysed. The survey was conducted during fall 2008 and spring 2009. The questionnaire design was made in a web-based questionnaire software tool in 2008 . It was tested internally within the department as well as on 5 industrial parts (a total of 15 test questionnaires was sent, wherefrom 5 answered). After minor changes in the design, the questionnaire was sent to the study participants during September 2008 to February 2009. A telephone call to the respondent was preceding the sending out to assure that correct person within the company was receiving the questionnaire. The questionnaire consisted of 29 questions in total: Company descriptive (Questions 1-6), Maintenance related descriptive (Questions 7-18), IT use related questions (Questions 19-23) and IT procurement related questions (Questions 24-29). Two additional questions were included regarding the wish to be contacted for further interviews.

\subsection{Survey participants}

For this cross-sectional survey among Swedish production plants were selected using information from Swedish Centre for Maintenance Management containing contact information regarding production plants in Sweden. The population for our study consists of plants where the maintenance is performed in-house and where contact information regarding maintenance managers was available. The size of the population was 381. Of these 175 respondents could not be reached by telephone and were removed from the study and an additional 8 respondents stated that they could not participate by various reasons. This resulted in 198 respondents. The total number of respondents was 71 representing a response rate of 34\%.

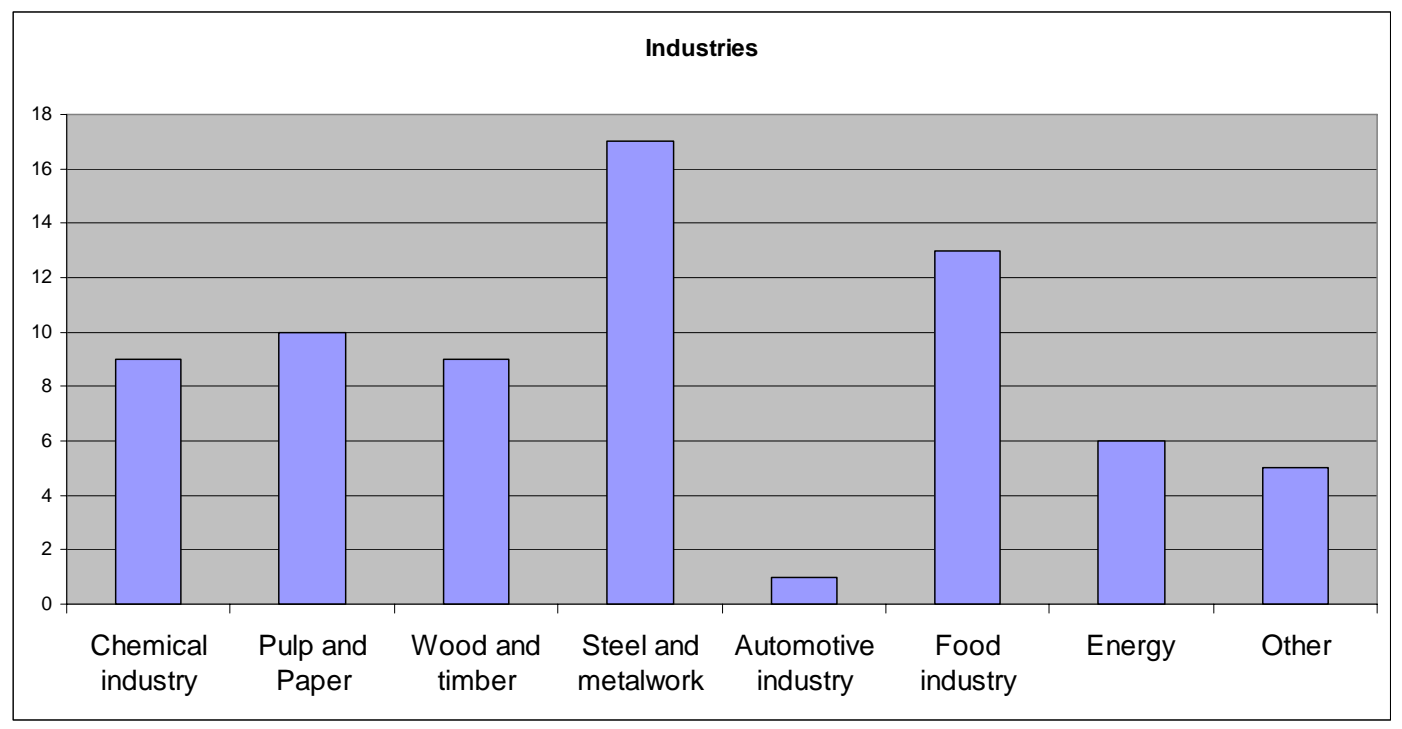

Figure 3. Respondents

The respondents represented the following industries: Chemical industry, Pulp and Paper, Wood and Timber, Steel and Metalwork, Automotive industry, Food industry, Energy and Other, see Figure 3.

\subsection{Functionality gaps in MMIT}

From the questionnaire two questions are of special interest for this paper, Q23 and Q24. The first describes different activities within maintenance management and the respondents were asked to tell whether these were made manually, with support by IT, or not at all. In addition, they were asked if the functionality was present in the current IT system but not utilised, and if the functionality was not present in the IT system but needed. Table 1 presents the results from the two latter 
parts of the question. The Q24 is similar to the first one, but is focusing on information needed for maintenance management. Table 2 presents the results of the part of the question requiring about whether the information was present in the current IT system used for maintenance management but not used and if the information was not present in the IT system.

Table 1

Functionality gaps in percentages

\begin{tabular}{lrr} 
& $\begin{array}{c}\text { Support is not present in } \\
\text { the current IT system but is } \\
\text { needed (Percentages) }\end{array}$ & $\begin{array}{l}\text { Support is present in the } \\
\text { current IT system but not } \\
\text { used (Percentages) }\end{array}$ \\
\hline Work order handling & 0,0 & 12,7 \\
Preventive maintenance planning & 1,4 & 11,3 \\
Spare parts planning & 2,8 & 8,5 \\
Personnel planning & 4,2 & 15,5 \\
Budgeting & 5,6 & 5,6 \\
Failure reporting & 1,4 & 11,3 \\
Unplanned maintenance execution & 0,0 & 11,3 \\
Planned maintenance execution & 0,0 & 8,5 \\
Measurement and controlling & 2,8 & 11,3 \\
Plant register handling & 0,0 & 5,6 \\
Spare parts management & 0,0 & 7,0 \\
Material purchasing & 0,0 & 5,6 \\
Cost control & 1,4 & 14,1 \\
Analysis of conducted maintenance & 2,8 & 12,7 \\
Failure cause and conseq. analysis & 7,0 & 22,5 \\
Analysis of CM data & 4,2 & 15,5 \\
Improvement analysis of maintenance & 7,0 & 16,9 \\
Technical imp. analysis of production & 5,6 & 8,5 \\
Economic imp. analysis of production & 4,2 & 9,9 \\
\hline
\end{tabular}

The leftmost column in Table 1 lists various functionality of MMIT. The second column accounts for the results concerning RQ1a (Does a gap between IT system functionality coverage and IT system functionality demands exist?) and in the third column results for RQ1b (Does a gap between IT system functionality coverage and IT system functionality use exist?) are found. From Table 1 we can see that the required functionality is in general present in the IT systems used. Only in the area of analysis some lack of functionality is to be noted (Failure cause and consequence analysis and Improvement analysis of maintenance), but it is still quite modest. The difference between required functionality and functionality provided by the IT systems is higher: many respondents have recognised that their IT systems contain more functionality than they actually use. The functionalities that were mostly unused, in ascending order, are:

- $\quad$ Failure cause and consequence analysis (22,5\%),

- Improvement analysis of maintenance (16,9\%),

- Analysis of condition monitoring data and Personnel planning (15,5\%),

- Cost control (14,1\%), and

- Work order handling and Analysis of conducted maintenance (12,7\%). 
Table 2

Information gaps in percentages

\begin{tabular}{|c|c|c|}
\hline & $\begin{array}{l}\text { Information is not present in } \\
\text { the current IT system but is } \\
\text { needed (Percentages) }\end{array}$ & $\begin{array}{l}\text { Information is present in the } \\
\text { current IT system but not } \\
\text { used (Percentages) }\end{array}$ \\
\hline Plant register & 1,4 & 4,2 \\
\hline Spare parts list & 0,0 & 2,8 \\
\hline Tools list & 5,6 & 8,5 \\
\hline Personnel & 5,6 & 8,5 \\
\hline Maintenance policy and objectives & 2,8 & 4,2 \\
\hline Maintenance instructions and procedures & 4,2 & 5,6 \\
\hline Maintenance follow up procedures & 7,0 & 8,5 \\
\hline OEM recommendations & 5,6 & 9,9 \\
\hline Technical specifications and drawings & 2,8 & 4,2 \\
\hline Maintenance budget & 5,6 & 0,0 \\
\hline Production plan & 2,8 & 0,0 \\
\hline Planned work orders & 0,0 & 1,4 \\
\hline Work order schedule & 1,4 & 4,2 \\
\hline Spare parts in inventory & 0,0 & 2,8 \\
\hline Work order history & 0,0 & 2,8 \\
\hline Maintenance costs & 1,4 & 7,0 \\
\hline Failure history & 2,8 & 9,9 \\
\hline Measurement history & 4,2 & 7,0 \\
\hline Failure cause and conseq. analysis & 5,6 & 9,9 \\
\hline Maintenance improvement suggestions & 9,9 & 12,7 \\
\hline
\end{tabular}

Table 2 contains a similar summary of the results as Table 1, but regarding information contents. The leftmost column in Table 2 lists information held by MMIT. The second column accounts for the results concerning RQ2a (Does a gap between information coverage and information demands exist?) and in the third column results for RQ2b (Does a gap between information coverage and information use exist?) are found. In general, the information coverage of the IT systems is high. Missing information is mainly found in the area of follow up and improvement (Maintenance improvement suggestions and Maintenance follow up procedures). The IT systems do not contain unnecessary information to high extent either. The information that most respondents found unused were:

- Maintenance improvement suggestions (12,7\%),

- $\quad$ OEM recommendations, Failure history and Failure cause and consequence analysis information (9,9\%), and

- $\quad$ Tools list, Personnel and Maintenance follow up procedures $(8,5 \%)$

\subsection{Functionality gaps depending on type of IT system}

In the next step, results from Q23 and Q24 were analysed with respect to which type of IT system the company use. For this purpose Q20 was utilised. This question asked about the type of IT system the respondent use for maintenance management (The respondent could pick one or more type). IT system types included were ERP system, production system, CMMS, special designed system and others. In the further analysis the type "others" is not included. A cross-tabular analysis was made to determine if there were significant differences in functionality and information gaps depending on which IT system the respondent use, compared to the other IT system types. The differences were stated as significant at the $\mathrm{p}<0,05$ level. Table 3 lists all significant differences found. 
Table 3

Significant differences depending on IT system type

\begin{tabular}{|c|c|c|c|c|c|c|}
\hline & present is & e curre & \multirow{2}{*}{\multicolumn{2}{|c|}{$\begin{array}{l}\text { I-system but not usec } \\
\text { Production system }\end{array}$}} & \multirow{2}{*}{\multicolumn{2}{|c|}{ CMMS }} \\
\hline & \multicolumn{2}{|c|}{$\begin{array}{l}\text { present in the curre } \\
\text { ERP system }\end{array}$} & & & & \\
\hline & $\begin{array}{c}\text { Not used } \\
n=39\end{array}$ & $\begin{array}{l}\text { Used } \\
\mathrm{n}=32\end{array}$ & $\begin{array}{l}\text { Not used } \\
n=50\end{array}$ & $\begin{array}{c}\text { Use } \\
\mathrm{n}=21\end{array}$ & $\begin{array}{c}\text { Not used } \\
n=12\end{array}$ & $\begin{array}{l}\text { Used } \\
\mathrm{n}=59\end{array}$ \\
\hline Work order handling & $\begin{array}{c}+ \\
\chi^{2}=4,801\end{array}$ & $\begin{array}{c}- \\
0,028\end{array}$ & & & & \\
\hline Personnel planning & & & $\chi^{2}=7,249$ & $\begin{array}{c}+ \\
=0,007\end{array}$ & & \\
\hline $\begin{array}{l}\text { Failure cause and consequence } \\
\text { analysis }\end{array}$ & & & & & $\chi^{2}=4,20$ & $\stackrel{+}{+}=0,040$ \\
\hline
\end{tabular}

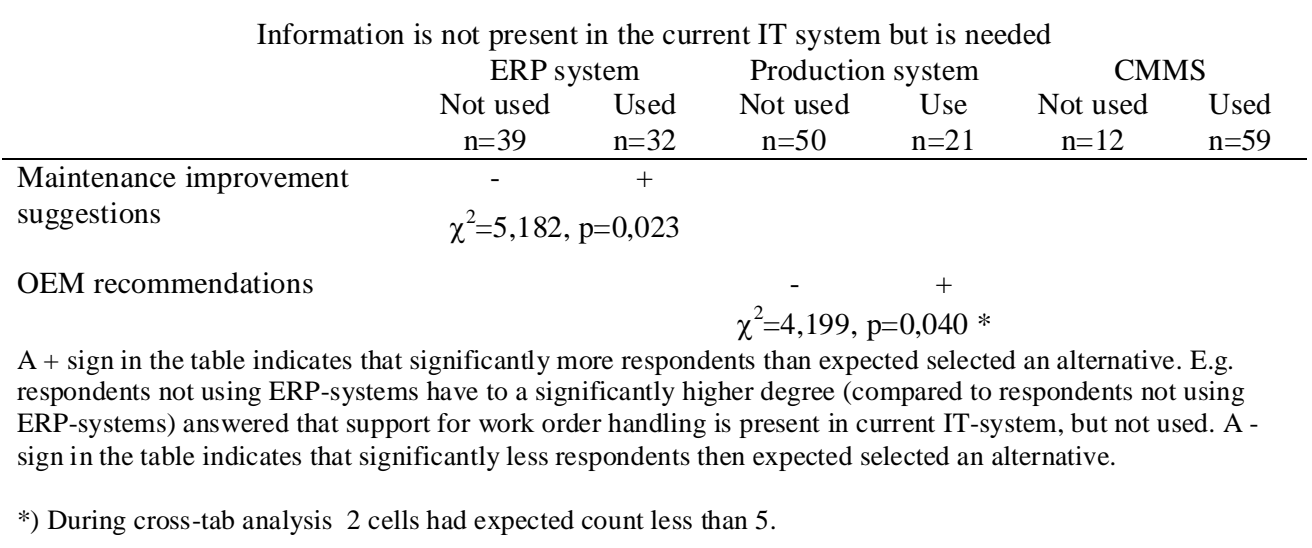

From Table 3 we find that those not using ERP systems, compared to those using ERP, functionality regarding work order handling was to a significant degree present but not used. Furthermore, those using ERP state that there is a lack of information regarding maintenance improvements suggestions in their system.

Those using production systems have stated that there is support for personnel planning in their systems but that it is not used (to a higher degree compared to those not using production systems). Additionally, those using production systems state that there is a lack of information regarding OEM recommendations to a higher degree compared to those not using production systems.

Those using CMMS state that there is support for failure cause and consequence analysis present but it is not used to a higher degree compared to those not using CMMS.

\section{RESULTS AND CONCLUSIONS}

In section two, four questions regarding functionality gaps in maintenance management IT were formulated:

RQ1a: Does a gap between IT system functionality coverage and IT system functionality demands exist?

RQ1b: Does a gap between IT system functionality coverage and IT system functionality use exist?

RQ2a: Does a gap between information coverage and information demands exist?

RQ2b: Does a gap between information coverage and information use exist?

The analysis showed that all types of functionality gaps did exist. In general, the functionality gaps connected to RQ1a and RQ2a were modest, while the gaps connected to RQ1b and RQ2b were existent to a slightly higher degree. The most commonly functions missing were failure cause and consequence analysis and maintenance improvement analysis, and the most commonly missing information was maintenance improvement suggestions. Notable is that the most commonly unused function was failure cause and consequence analysis and the most commonly unused information was maintenance improvement suggestions, thus the same functions appears as both missed and unused. The functionality gaps for all MMIT studied are summarised in Figure 4. 


\begin{tabular}{|l|l|l|}
\multicolumn{2}{l}{ Missing } & \multicolumn{2}{l}{ Unused } \\
\cline { 3 - 4 } Functionality & Failure cause and consequence analysis & $\begin{array}{l}\text { Failure cause and consequence analysis } \\
\text { Improvement analysis of maintenance } \\
\text { Analysis of condition monitoring data } \\
\text { Improvement analysis of maintenance } \\
\text { Personnel planning } \\
\text { Cost control } \\
\text { Work order handling }\end{array}$ \\
\cline { 3 - 3 } & & \\
\cline { 2 - 3 } & & Maintenance improvement suggestions \\
& Maintenance improvement suggestions & OEM recommendations \\
& Maintenance follow up procedures & Failure history \\
& & Failure cause and consequence analysis inf. \\
& Tools list \\
& Personnel \\
& & Maintenance follow up procedures \\
\hline
\end{tabular}

Figure 4. Functionality gaps found

The gaps were furthermore analysed with respect to the type of IT system used. Figure 5 summarises the findings with respect to IT system type. The results indicate that ERP-systems and production systems do not include all required information for maintenance management and that all IT systems except the ERP systems contains some unused functionality.

The lack of information for maintenance improvement suggestions that was included in Figure 4 might be explained by the ERP users: they apprehended to higher degree, compared to those using other types of IT, that they lacked information regarding maintenance improvement suggestions. Similarly, the functionalities personnel planning, work order handling and failure cause and consequence analysis, which were listed as unused in Figure 4, could be explained by IT system type. All general gaps in Figure 4 could not be explained by IT system type though. Moreover, one piece of information was apprehended as missing for those using a production system, compared to the MMIT in general.

\begin{tabular}{|c|c|c|}
\hline & $\begin{array}{l}\text { Missing } \\
\text { ERP }\end{array}$ & Unused \\
\hline \multirow[t]{2}{*}{ Information } & Maintenance improvement suggestions & \\
\hline & Production & \\
\hline \multirow{3}{*}{$\begin{array}{l}\text { Functionality } \\
\text { Information }\end{array}$} & & $\begin{array}{l}\text { Personnel planning } \\
\text { Work order handling }\end{array}$ \\
\hline & OEM recommendations & \\
\hline & CMMS & \\
\hline \multirow{2}{*}{$\begin{array}{l}\text { Functionality } \\
\text { Information }\end{array}$} & & $\begin{array}{l}\text { Failure cause and consequence analysis } \\
\text { Work order handling }\end{array}$ \\
\hline & Special & \\
\hline \multirow{2}{*}{$\begin{array}{l}\text { Functionality } \\
\text { Information }\end{array}$} & & Work order handling \\
\hline & & \\
\hline
\end{tabular}

Figure 5. Functionality gaps for specific IT system

The analysis presented in this paper has revealed some interesting results. The research questions have to some extent been answered, but the problem is complex in its nature, therefore additional research is required. One possibility is that the gaps are dependent on other factors than IT system type. Therefore, further analysis of other factors, such as industry type, production type or maintenance organisation will be made. The statistical analysis will also be combined with qualitative methods in form of interviews. The results of this paper will therefore be utilised when designing the interview template. 


\section{REFERENCES}

1 Dedrick, J., Gurbaxani, V. and Kraemer, K. L. (2003) Information Technology and Economic Performance: A Critical Review of the Empirical Evidence. ACM Computing Surveys, 35(1), 1-29.

2 Jonsson, P. (2000) Towards an holistic understanding of disruptions in Operations Management. Journal of Operations Management, 18, 701-718.

3 Pintelon, L., Pinjala, S. K. and Vereecke, A. (2006) Evaluating the effectiveness of maintenance strategies. Journal of Quality of Maintenance Engineering, 12(1), 7-20.

4 Liptrot, D. and Palarchio, E. (2000) Utilizing advanced maintenance practices and information technology to achieve maximum equipment reliability. International Journal of Quality \& Reliability Management, 17(8), 919-928.

5 Mjema, E. A. M. and Mweta, A M. (2003) An analysis of economics of investing in IT in the maintenance department An empirical study in a cement factory in Tanzania. Journal of Quality in Maintenance Engineering, 9(4), 411-435.

6 O'Donoghue, C. D. and Prendergast, J. G. (2004) Implementation and benefits of introducing a computerised maintenance management system into a textile manufacturing company. Journal of Materials Processing Technology, 153-154, 226-232.

7 Labib, A.W. (2004) A decision analysis model for maintenance policy selection using a CMMS. Journal of Quality in Maintenance Engineering, 10(3), 191-202.

8 Swanson, L. (1997) Computerized maintenance management systems: a study of system design and use. Production and inventory management journal, 3, 11-14.

9 Jonsson, P. (1997) The Status of Maintenance Management in Swedish Manufacturing Firms. Journal of Quality in Maintenance Engineering, 3(4), 233-258.

10 Alsyouf, I. (2004) Cost effective maintenance for competitive advantages, PhD thesis. Växjö: Växjö University Press.

11 Beynon-Davies, P. (2002) Information Systems, An introduction to Informatics in Organisations. Bath: Palgrave.

12 DeLone, W. H. and McLean, E. R. (1992) Information Systems Success: The Quest for the Dependent Variable. Information Systems Research, 3(1), 60-96. 